\title{
Morphine overdose from error propagation on an acute pain service
}

\author{
[Une surdose de morphine résultant de multiples erreurs dans un service de \\ douleur aiguë]
}

Summer Syed MD, James E. Paul MD FRCP(C), Molly Hueftlein RN, Marianne Kampf RN BSCN, Richard F. McLean MD FRCP(C)

Purpose: To highlight a case in which multiple errors occurred during programming and administration of analgesia via a patient-controlled analgesia (PCA) pump, and to formulate recommendations on how to avoid such errors in the future.

Clinical features: Following lumbar surgery, a 43-yr-old woman was switched from epidural analgesia to a PCA pump. This change was associated with numerous errors at several points of delivery of her care. Errors included incorrect connection of the PCA adapter, incorrect pump programming, and communication lapses which resulted in a morphine overdose and subsequent respiratory arrest. The patient was promptly resuscitated, and she had an uneventful recovery. The event resulted in a complete review of pain management equipment and the training and education of staff using this equipment at our institution.

Conclusion: This case highlights how multiple individual errors can combine to result in a serious adverse event. While equipment design was an important factor in this adverse event, human factors played a critical role at multiple levels.

Objectif : Présenter un cas où de multiples erreurs sont survenues pendant la programmation et l'administration de l'analgésie autocontrôlée $(A A C)$ et formuler des recommandations sur les moyens d'éviter ces erreurs à l'avenir.

Éléments cliniques : Après une intervention chirurgicale lombaire, l'analgésie péridurale a été remplacée par une pompe d'AAC chez une femme de 43 ans. Ce changement a été suivi de nombreuses erreurs dont la connexion incorrecte de l'adaptateur d'AAC, une programmation inexacte de la pompe et des omissions dans les communication qui ont mené à une surdose de morphine et à un arrêt respiratoire subséquent. La patiente, rapidement réanimée, s'est bien rétablie. Cet événement a conduit à l'examen complet du matériel de traitement de la douleur et à la formation et à l'éducation du personnel qui utilise le matériel dans notre institution.

Conclusion : Ce cas souligne comment de multiples erreurs individuelles peuvent, en se combinant, provoquer un grave événement indésirable. La conception du matériel a été un facteur important, mais des facteurs humains y ont joué un rôle critique.

$\mathrm{P}$ ATIENT controlled analgesia (PCA) is a computer-based medical technology designed to provide safe, self-administration of analgesics for the management of postoperative pain. ${ }^{1}$ The potential benefits of PCA include improved pain management with fewer side effects, by the administration of more frequent but smaller doses of analgesics. This technology allows for better utilization of nursing resources, with decreased fluctuation in blood analgesic levels. Unfortunately, analgesics are a leading cause of adverse drug events; $;^{2,3}$ and PCA, compared to narcotic administration by other routes, has a similar incidence of severe respiratory depression $(<1 \%)^{4,5}$ The incidence of PCA associated respiratory depression varies from 0.3 to $6 \%$ depending on the patient population and definition of respiratory depression. ${ }^{6-8}$

Numerous reports of safety hazards and deaths associated with PCA pumps have been reported in the literature since the introduction of this technology. ${ }^{4,5,8-21}$ The following report is a case of respiratory

From the Department of Anesthesia, Hamilton Health Sciences, McMaster University, London, Ontario, Canada. Address correspondence to: Dr. Richard F. McLean, Department of Anesthesia, 237 Barton Street East, Hamilton, Ontario L8L 2X2,

Canada. Phone: 905-527-4322, ext. 46698; Fax: 905-577-8023; E-mail: mcleanr@hhsc.ca

Accepted for publication August 30, 2005.

Revision accepted January 24, 2006.

Competing interests: None declared. 
arrest associated with PCA morphine, and illustrates the multiple levels at which errors can occur with PCA administration. Consent was obtained from the patient for use of personal health information in this case report in accordance with our institutional guidelines.

\section{Case report}

A 43-yr-old, $102 \mathrm{~kg}$ woman underwent lumbar decompression and fusion surgery. She had a past medical history of polycystic ovarian syndrome, depression, and chronic back pain. She was receiving oxycocet and Tylenol \#3 prn prior to her surgery. While the daily doses were not documented, she required these medications on an occasional basis only. An epidural catheter was placed intra-operatively at the surgical site. An infusion of bupivacaine $0.125 \%$ with fentanyl $5 \mu \mathrm{g} \cdot \mathrm{mL}^{-1}$ was infused at an initial rate of $6 \mathrm{~mL} \cdot \mathrm{hr}^{-1}$. Demerol $15-50 \mathrm{mg}$ epidurally q $2 \mathrm{~h}$ prn for breakthrough pain was ordered. The patient received one dose of demerol $25 \mathrm{mg}$ while in the postanesthesia care unit (PACU), and two subsequent boluses on postoperative day one (POD 1). Because of ongoing difficulties with the catheter, a decision was made to switch to a patient-controlled analgesia (PCA) pump (Abbot Lifecare PCA Plus II Infuser, Abbot Laboratories, North Chicago, IL, USA) on the morning of postoperative day two (POD 2). At this point, the epidural infusion rate was $10 \mathrm{~mL} \cdot \mathrm{hr}^{-1}$. The change was ordered by an anesthesiologist, and medications were prepared by the ward nurses according to standard protocol (morphine $5 \mathrm{mg}$ loading dose, up to a total of $15 \mathrm{mg}$, morphine $5 \mathrm{mg} \cdot \mathrm{mL}^{-1}, 2 \mathrm{mg}$ PCA dose, ten-minute lockout, no four hour maximum).

The primary nurse (A) caring for the patient was uncertain how to program the pump, and sought the assistance of a second nurse (B). Together they programmed the pump, referring to the attached instructions. Two errors were made at the time of programming; the first error was to incorrectly attach the PCA tubing to the PCA extension set. A back-check valve is incorporated into this set, which is connected to the patient's main $i v$ tubing. The PCA set plugs into the limb of the Y-connector which does not have a back-check valve. The purpose of this connector is to ensure that the medication administered has unidirectional flow, and will not reflux in a retrograde manner into the main $i v$ tubing. A second error was incorrect programming of the morphine concentration, which was set at $0.5 \mathrm{mg} \cdot \mathrm{mL}^{-1}$ instead of $5 \mathrm{mg} \cdot \mathrm{mL}^{-1}$. This setting resulted in the administered dose being ten times greater than the prescribed dose (in this case, 20 $\mathrm{mg}$ boluses, instead of $2 \mathrm{mg}$ ).
The patient proceeded to use the PCA pump (initiated at 11:24 hr on POD 2); however she was not getting relief from her pain. Because of the programming error, she self-administered the entire pre-filled syringe (153 mg of morphine) over $90 \mathrm{~min}$. However, she suffered no ill effects at this time, likely because the back check valve was incorrectly attached, and the administered morphine backed up into the iv tubing and into an empty antibiotic mini-bag which had been piggy-backed into the main iv line earlier in the day.

The empty syringe alarm sounded 90 min after the patient started using the pump, and a third nurse (C) responded, and changed the syringe. This nurse suspected an error in the drug concentration and notified nurse $\mathrm{B}$. Ten minutes later, nurse $\mathrm{B}$ changed the concentration setting to $5 \mathrm{mg} \cdot \mathrm{mL}^{-1}$. As the patient was awake, alert, and had no complaints, no further investigation was performed, and no report was generated. The patient continued to use the PCA pump, still with no significant relief. She self-administered another $34 \mathrm{mg}$ of morphine over the ensuing three hours. In addition, she received two supplemental morphine boluses $5 \mathrm{mg}$ iv from nursing staff, for breakthrough pain.

At 17:00 hr another nurse (D) responded to a call from the patient for assistance because of persistent pain. The patient expressed concern that her iv was not running properly. The nurse examined the $i v$ and noted that the PCA was incorrectly attached to the patient. She corrected the position of the back check valve. The $i v$ was indeed running poorly, and the nurse flushed it with saline. She then left the room. Shortly after flushing the iv the patient's level of discomfort decreased significantly, and she became drowsy. Her daughter who was in attendance, reported that her mother was feeling "weird". The daughter asked the nurses about the change in her mother's sensorium, and was reassured that her mother was just experiencing the medication taking effect.

At 17:10 hr the staff anesthesiologist visited the patient during routine pain rounds. The patient was found to be cyanosed, somnolent and apneic. Resuscitative measures were instituted with bag and mask ventilation, the patient received naloxone $(0.4$ $\mathrm{mg}$ ) and was transferred to the PACU for further observation. The PCA attachment was changed again at the request of the anesthesiologist. The patient made a full recovery and there were no adverse sequelae. Full disclosure was made to the patient by the chief of anesthesiology and the nurse manager regarding the error in the PCA settings and the subsequent overdose of morphine resulting in respiratory arrest. The historical data from the pump was downloaded. 
This data, along with meticulous review of the chart and interviews with the involved staff, allowed for a complete outline of the events leading to this critical event.

\section{Discussion}

As a result of this case, a multidisciplinary panel was established to review the incident and provide recommendations in order to prevent such events from occurring in the future. The members of this committee included pain service nurses, PACU nurses, a clinical nurse educator, the director of the pain service, and the chief of the department of anesthesia. The review team made the following recommendations: 1) develop an educational and mentoring program to ensure that ward nurses are aware of how to program the PCA and epidural pumps; 2) provide refresher training in epidural and PCA usage annually to all surgical nursing staff; 3 ) revise the nursing policy on set up and programming of PCA pumps, to more closely follow the recommendations from the Institute of Safe Medical Practice, ${ }^{15} 4$ ) review PCA and epidural pump settings during patient handover and at each change of shift; 5) replace the Abbott Lifecare $4100 \AA$ pump with more up to date technology; 6) institute mandatory critical incident reporting.

The potential human errors associated with PCA, and the errors illustrated by this case are summarized in the Table. ${ }^{22,23}$ As shown in the Table, this case demonstrated six of 17 potential errors associated with the PCA pump. While there was no actual transfer of patient care, the settings were not appropriately reviewed at the time of initiation. In addition, the programming error identified by nurse $\mathrm{C}$ did not result in an adequate review of the settings, and identification of the potential consequences of the error.

The concentration programming error made with the Abbot LifeCare ${ }^{\circledR} 4100$ pump in this case has been reported previously. ${ }^{20}$ The interface of this pump offers a low default setting as the initial choice, and the most common programming error is to enter the default concentration. This type of error has resulted in several deaths from respiratory arrest. ${ }^{16-18}$ The selection of a concentration of $0.5 \mathrm{mg} \cdot \mathrm{mL}^{-1}$ resulted in a dose ten times greater than that which was ordered. Although the machine has a "four-hour limit", the incorrect programming in this case would negate this limit check on the machine since the machine would assume the $30 \mathrm{~mL}$ syringe contained only $15 \mathrm{mg}$ of morphine, instead of the contained drug mass of 150 $\mathrm{mg}$. A human factors engineering approach to designing the programming interface has been shown to reduce programming errors. ${ }^{22}$ In addition, the imple-
TABLE Potential human errors associated with PCA opioid administration

\begin{tabular}{ll}
\hline Potential error & $\begin{array}{l}\text { Occurrence in } \\
\text { this case report }\end{array}$ \\
\hline PCA an inappropriate modality choice for patient & No \\
PCA tubing incorrectly connected to the & Yes \\
pump or patient & No \\
Error in drug order by physician & No \\
Wrong drug supplied by pharmacy & Yes \\
Error in PCA pump programming & No \\
$\quad$ Purge & Yes \\
$\quad$ Concentration & No \\
Bolus & No \\
$\quad$ Mode & No \\
$\quad$ Lockout interval & No \\
4-hr limit & No \\
$\quad$ Continuous dose & No \\
Inadequate review of PCA settings on transfer & Yes \\
of nursing care & \\
Inadequate documentation and notification & Yes \\
of PCA problems by ward nurse & \\
Insufficient monitoring of patient while on PCA & No \\
Inappropriate management of recognized & Yes \\
PCA complication/error & \\
\hline PCA = patient-controlled analgesia. &
\end{tabular}

mentation of bar code technology promises to further reduce the risk of programming errors. ${ }^{24}$

Neither of the two nurses involved in the initial programming was familiar with the programming of these pumps. This has led to a review of the policy for PCA and epidural pump set up. It now incorporates a checklist to be independently completed by two nurses competent in this area, thus clarifying the performance of "double-checks". The policy also requires that at patient handover and at each change of shift, the settings are reviewed and documented by the accepting nurse. The policy incorporates many of the recommendations from the Institute for Safe Medication Practices. ${ }^{15}$ It also addresses the role of the PACU in supporting the acute pain service in settings where patients may be a monitored unit for a limited period of time.

Compounding the programming error was the misplacement of the back-check valve, which allowed a large reservoir of morphine to accumulate, most likely in the empty antibiotic bag. This prevented the initial programming error from being recognized. The patient was complaining of pain after $153 \mathrm{mg}$ of morphine had been delivered from the pump over a period of $90 \mathrm{~min}$. This should have alerted the nurses to a potential problem with the system. While nurse 
C did identify a programming error, neither she nor nurse $B$ investigated the issue of where the $150 \mathrm{mg}$ of morphine had been injected, nor did the nurses alert the pain service to a potential problem. In our institution, the majority of PCA pumps are initiated and programmed in the PACU. Thus, the ward nurses receive limited exposure to this skill. Hence, the review committee's recommendation for an enhanced educational program ensued. This matter is also being addressed by a monthly orientation session in the PACU, as well as a mentoring program that enables ward nurses to work with experienced PACU nurses, and to participate in the setup of PCA pumps. Refresher training is incorporated into an annual skills day which all nurses in the institution are required to attend.

The final opportunity to avoid the overdose occurred when nurse $\mathrm{D}$ arrived in response to the patient's ongoing lack of pain control and voiced concerns about the status of the patient's $i v$. She recognized that the back-check valve was incorrectly attached; however she assumed that the antibiotic bag contained cefazolin. When she flushed the $i v$ line and allowed its contents to be administered, a massive dose of morphine was delivered. An assumption had also been made that the patient's rapid change in level of pain and the onset of drowsiness represented an appropriate response to morphine. However, given that she was not the primary nurse caregiver for this patient, it is understandable that this nurse was unaware as to when the antibiotic had been hung, and that it potentially contained morphine. Multiple caregivers involved in this patient's care likely contributed to the adverse event. Staffing and work assignments and coverage for breaks often allow little time for troubleshooting and analyzing issues surrounding one patient.

Critical incident reporting on the acute pain service continues to improve steadily. The results of this review have been disseminated widely to all areas of the hospital involved in the care of patients with PCA and epidural pumps to avoid such potentially lethal errors in the future. The case presented demonstrates the clinical impact of error propogation on an acute pain service. While the primary error involved incorrect programming of the PCA pump, the problem was compounded by multiple other faults in the chain of events. System errors such as these need to be reported and investigated to ensure that the lessons learned result in the safest possible use of PCA technology in the perioperative setting.

\section{References}

1 Ferrante FM, Ostheimer GW, Covino BG. Patient-

Controlled Analgesia. Boston: Blackwell Scientific; 1990.
2 Classen DC, Pestotnik SL, Evans RS, Burke JP. Computerized surveillance of adverse drug events in hospital patients. JAMA 1991; 266: 2847-51.

3 Bates DW, Cullen DJ, Laird N, et al. Incidence of adverse drug events and potential adverse drug events. Implications for prevention. ADE Prevention Study Group. JAMA 1995; 274: 29-34.

4 Baxter AD. Respiratory depression with patient-controlled analgesia (Editorial). Can J Anaesth 1994; 41: 87-90.

5 Etches $R C$. Respiratory depression associated with patient-controlled analgesia: a review of eight cases. Can J Anaesth 1994; 41: 125-32.

6 Paul JE, Sawhney M, Beattie WS, McLean RF. Critical Incidents amongst 10033 acute pain patients. Can J Anesth 2004; 51: A22 (abstract).

7 Lehmann KA, Grond S, Freier J, Zech D. Postoperative pain management and respiratory depression after thoracotomy: a comparison of intramuscular piritramide and intravenous patient-controlled analgesia using fentanyl or buprenorphine. J Clin Anesth 1991; 3: 194-201.

8 Doyle DJ, Vicente KJ. Patient-controlled analgesia (Letter). CMAJ 2001; 164: 620-1.

9 Doyle J, Vicente KJ. Electrical short circuit as a possible cause of death in patients on PCA machines: report on an opiate overdose and possible preventive remedy (Letter). Anesthesiology 2001; 94: 940.

10 Anonymous. Abbott PCA Plus II patient-controlled analgesic pumps prone to misprogramming resulting in narcotic overinfusions. Health Devices 1997; 26: 389-91.

11 Geller RJ. Meperidine in patient-controlled analgesia: a near-fatal mishap. Anesth Analg 1993; 76: 655-7.

12 Grover ER, Heath ML. Patient-controlled analgesia. A serious incident. Anaesthesia 1992; 47: 402-4.

13 Institute for Safe Medication Practices. Evidence builds: lack of focus on human factors allows error-prone devices. ISMP Medication Safety Alert 1999; 4: 1-2.

14 Institute for Safe Medication Practices. Misprogram a PCA pump? It's easy! ISMP Medication Safety Alert 2004; 9: 15.

15 Institute for Safe Medication Practices. Safety issues with patient controlled analgesia. Part I - How errors occur. ISMP Medication Safety Alert 2003. Available from URL; ismp.org/Newsletters/acutecare/articles/20030710.asp.

16 Institute for Safe Medication Practices. Mandatory reporting programs: why we can't "look the other way". ISMP Medication Safety Alert 2000; 5: 2.

17 Kwan A. Overdose of morphine during PCA. Anaesthesia 1995; 50: 919.

18 Notcutt WG, Knowles P, Kaldas R. Overdose of opioid 
from patient-controlled analgesia pumps. Br J Anaesth 1992; 69: 95-7.

19 Weinger MB, Pantiskas C, Wiklund ME, Carstensen $P$. Incorporating human factors into the design of medical devices (Letter). JAMA 1998; 280: 1484.

20 White PF. Mishaps with patient-controlled analgesia. Anesthesiology 1987; 66: 81-3.

21 Vicente KJ, Kada-Bekhaled K, Hillel G, Cassano A, Orser $B A$. Programming errors contribute to death from patient-controlled analgesia: case report and estimate of probability. Can J Anesth 2003; 50: 328-32.

22 Lin L, Vicente KJ, Doyle DJ. Patient safety, potential adverse drugs events, and medical device design: a human factors engineering approach. J Biomed Inform 2001; 34: 274-84.

23 Doyle DJ. Programming errors from patient-controlled analgesia (Letter). Can J Anesth 2003; 50: 855.

24 Abbott Laboratories. Abbott Laboratories introduces the LifeCare PCA3 infusion system. a state-of-theart patient-controlled analgesia device. Available from URL; http://abbott.com/news/press_release. cfm?id=551 (April 29, 2003). 